This item was submitted to Loughborough's Research Repository by the author.

Items in Figshare are protected by copyright, with all rights reserved, unless otherwise indicated.

\title{
Layer thickness and draft angle selection for stereolithography injection mould tooling
}

PLEASE CITE THE PUBLISHED VERSION

http://dx.doi.org/10.1080/00207540110091875

VERSION

SMUR (Submitted Manuscript Under Review)

LICENCE

CC BY-NC-ND 4.0

\section{REPOSITORY RECORD}

Harris, Russell A., Neil Hopkinson, H.A. Newlyn, Richard J.M. Hague, and Phill M. Dickens. 2019. "Layer Thickness and Draft Angle Selection for Stereolithography Injection Mould Tooling". figshare.

https://hdl.handle.net/2134/4650. 
This item was submitted to Loughborough's Institutional Repository (https://dspace.lboro.ac.uk/) by the author and is made available under the following Creative Commons Licence conditions.

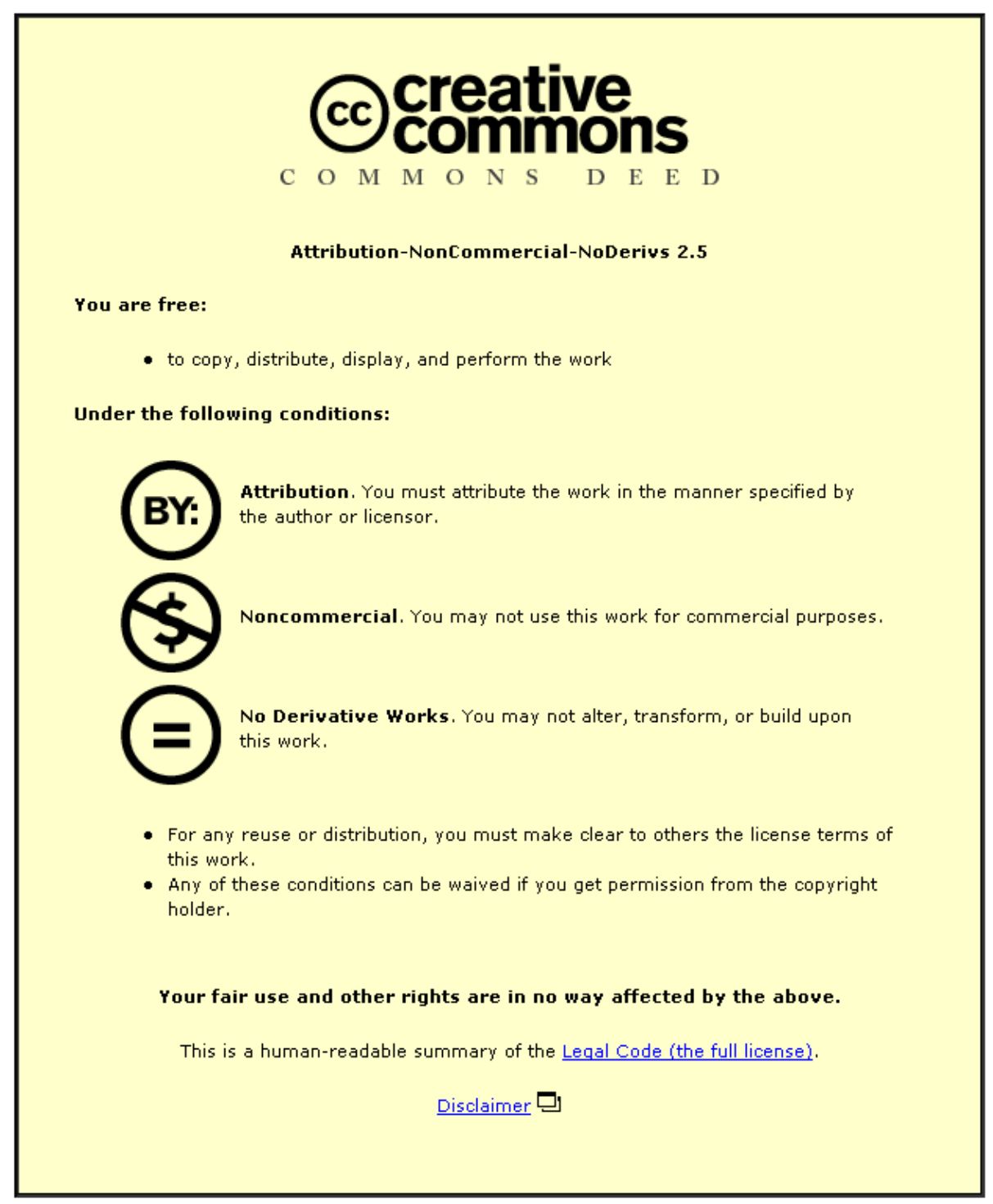

For the full text of this licence, please go to: http://creativecommons.org/licenses/by-nc-nd/2.5/ 


\section{Layer thickness and draft angle selection for stereolithography injection mould tooling}

Russ Harris AMIEE, Neil Hopkinson AMIEE, Phil Dickens MIMfgE and Richard Hague MIMechE.

Rapid Manufacturing Group, Department of Mechanical \& Manufacturing Engineering,

De Montfort University, Leicester, LE1 9BH, UK

Tel: 01162551551 Fax: 01162577052

Corresponding author: Russ Harris: rharris@dmu.ac.uk

Tel: 01162551551 ext.6649

Fax: 01162577052 


\section{Abstract}

The introduction of rapid prototyping has allowed engineers and designers to generate physical models of required parts very early on in the design and development phase. Further to this the use of stereolithography (SL) cavities as a rapid tooling method has allowed plastic prototype parts to be produced in their most common production manner; by injection moulding. The process is best suited to small production runs where the high costs of conventionally machined tooling is prohibitive.

One of the major drawbacks of the SL injection moulding process is the susceptibility of the tools to premature failure. SL tools may break under the force exerted by part ejection when the friction between a moulding and a core is greater than the tensile strength of the core resulting in tensile failure.

Very few justified recommendations exist concerning the choice of mould design variables that can lower the part ejection force experienced and reduce the risk of SL tool failure. This research investigates the ejection forces resulting from SL injection moulding tools which are identical in all respects except for their build layer thickness and incorporated draft angles in an attempt to identify appropriate evidence for recommendations with respect to these design variables and SL injection moulding. The results show that adjustment of draft angle results in a change of part ejection force as a reasonably linear relationship. An adjustment of the 
build layer thickness results in a change in part ejection force as a more non-linear relationship. The adjustment of build layer thickness had a greater effect on ejection force than the adjustment of draft angle. The results also show that the surface roughness of all tools remains unchanged after moulding a number of parts in polypropylene.

\section{Background}

\subsection{Stereolithography Tooling for Injection Moulding.}

The introduction of rapid prototyping has allowed engineers and designers to generate physical models of required parts very early in the design and development phase. However the requirements of such prototypes has now progressed beyond the validation of geometry's and onto the physical testing and proving of the parts. For such tests to be conducted the part must be produced in the material and by process intended for the production intent part. For injection moulded parts this situation highlights the requirement of a rapid mould making system that can deliver these parts within the time and cost boundaries. During the early years of stereolithography (SL) it was never envisaged that this process could be used to directly produce tooling. The glass transition temperature of SL parts available was only $\sim 65^{\circ} \mathrm{C}$ while the typical temperature of an injected polymer is $>200^{\circ} \mathrm{C}$ and early SL parts also suffered distortion. Despite these supposed limits successful results were achieved by SL users world-wide, including the Danish Technological Institute, Ciba 
Specialty Chemicals (now Vantico), the Fraunhofer Institute, the Queensland Manufacturing Institute and Xerox Corporation (Jacobs, 97). There exists other methods that could be used to create the required tooling to produce such mouldings, including resin cast moulds. These processes have been compared with SL injection moulding (Luck, 95) in the production of a typical quantity of parts, where the SL moulding process was found to be a superior alternative for producing design-intent prototypes.

SL injection moulding has also been compared with other direct RP mould generating techniques for producing a typical development quantity of mouldings. These RP methods included Cubital Solider (acrylic), EOS and Sintered glass filled nylon (Roberts, 98). Of these moulds only the SL moulds successfully produced the required number of parts and further more were still capable of producing further mouldings at the end of the trials.

It has also been noted that some of the other alternative techniques involve additional steps in the process, therefore becoming an indirect process and not really rapid tooling (Jayanthi, 97).

Other advantages of the process have been highlighted beyond the prototype validation phase; since the tool design has been verified the lead-time and cost involved in the manufacture of production tooling is reduced (Heath, 96). 


\subsection{Tool Failure During Part Ejection}

The most common source of failure in SL moulds has been described as the result of the required moulding contracting onto features in the core causing these features to break during ejection (Jacobs, 1996) (see Figure 1). Low tool strength especially at elevated temperatures has been cited as a contributory factor to failure.

Current recommendations for use of SL tools published by 3D Systems suggest that an extensive cooling period is needed prior to part ejection (Decelles, 1996). However research carried out at De Montfort University has suggested that as short a cooling time as possible should be adopted in order to gain a successful moulding (Hopkinson, 1998b). After part ejection, the tool should be allowed to cool sufficiently before the next part is moulded.

\subsection{Factors Contributing to the Ejection Force}

The ejection force required in injection moulding is governed by the static friction which exists between the mould and the moulded part and any effects caused by partial vacuums as the part is pushed from the mould (Menges, 1986). The static friction force is a function of the normal reaction between the mould and moulding, the coefficient of static friction between the mould and moulding and the area of contact between the mould and moulding parallel to the direction of ejection (Menges, 1986). Previous research has shown that the cooling time prior to ejection affects 
the normal reaction between the mould and moulding and therefore affects the ejection force required. By using different tools with identical dimensions the effects of partial vacuums may be nullified and by using a constant cooling time (and hence a constant normal reaction between the mould and moulding), the effects of the coefficient of static friction may be assessed (Hopkinson, 1998a).

For most material combinations the coefficient of friction between two bodies is governed by the surface roughness of their contacting surfaces. SL parts may be built with different layer thickness' which in turn result in different values of surface roughness. Tooling draft is used to reduce the force required for part removal. The extent of this draft angle results in the amount of change required to the geometry of a part/cavity. This research is aimed at assessing the effects of the layer thickness (and hence surface roughness) and tooling draft angle on the ejection force required.

\section{$3 \quad$ Research Methodology}

\subsection{Tool Design}

Figure 2 shows the core and cavity inserts used along with a sample moulding produced in this research. The moulding consists of a sprue, a closed cylinder which freezes onto the core and a lower flange which the ejection pins act upon. The cylinder is $40 \mathrm{~mm}$ long with a $20 \mathrm{~mm}$ outside diameter and $2 \mathrm{~mm}$ wall thickness. Three ejector pin holes are built into the core insert to facilitate part ejection. 
In order to assess the effects of layer thickness on ejection forces, three sets of inserts were produced. These inserts had layer thicknesses of $0.05 \mathrm{~mm}, 0.1 \mathrm{~mm}$ and $0.15 \mathrm{~mm}$. In order to assess the effects of tooling draft angle on ejection forces, another three sets of inserts were produced. These inserts had draft angles of $0.5^{\circ}, 1^{\circ}$ and $1.5^{\circ}$. All inserts were produced on an SLA350 SL machine using SL5190 resin. The inserts were oriented in the SLA vat in such a way as to ensure that the direction of ejection would be perpendicular to the layers (i.e. in the direction of the Z axis).

\subsection{Measurement of Surface Roughness}

Measurements of surface roughness were made before and after moulding to assess any smoothing which may occur during injection and ejection. Measurements of surface roughness were made at 12 fixed positions to (ensure repeatability between results) at a distance of $7 \mathrm{~mm}$ from the base of the core, 6 equally spaced points around the circumference of the core were measured for surface roughness. Another 6 equally spaced points around the core were measured at a distance of $7 \mathrm{~mm}$ from the top of the core.

\subsection{Injection Moulding Parameters}

The ejection forces were measured for 15 parts from each tool. Silicone based release agent spray was applied to both the core and cavity inserts 
prior to the $1^{\text {st }}$ and $11^{\text {th }}$ moulding. Melt injection was performed at 3 $\mathrm{cm}^{3} /$ second. No packing pressure was applied as no surface ripples due to cooling in the mould could be seen. A cooling period prior to ejection of 40 seconds was used as this had proved to be the optimum time in previous experiments (Hopkinson, 98a) with similar tools which allows minimum heat to be transferred into the tool while the part is still rigid enough to withstand ejection. For each moulding, the core temperature was allowed to cool to 55 degrees $C$ before the next shot was performed, this ensured that the tool was below its glass transition $(\mathrm{Tg})$ at the start of each cycle. The moulding material was polypropylene which was injected at 185 degrees $\mathrm{C}$.

\subsection{Measurement of Ejection Forces}

The ejection forces required were measured using strain gauge based load cells which were located behind the three ejector pins. The readings from the load cells were digitised using an analogue to digital converter. The digital signals were sampled at $1000 \mathrm{~Hz}$ and processed using HPVee visual programming software.

\section{$4 \quad$ Results}

\subsection{Surface Roughness Measurements}

The pre-moulding Ra measurements made from the draft angle inserts 
showed virtually no difference between the surface roughness of the cores for each of the angles utilised. The pre-moulding Ra measurements showed a strong relationship between build layer thickness and surface roughness i.e. layer thicknesses of $0.15,0.1 \& 0.05 \mathrm{~mm}$ resulted in $\mathrm{Ra}$ values of $15,10 \& 3$ ųm respectively. The mean Ra values of the post-moulding surface roughness for both layer thickness and draft angle tests are very similar to those found in the pre-moulding tests. There is no evidence to show that the tools are smoother after moulding with polypropylene.

\subsection{Ejection Forces}

Figure 3 indicates that cavities built with the thicker layers result in higher ejection forces in the SL moulding process. The increase in ejection force with larger layer thicknesses (and therefore higher surface roughness) is as expected because the higher the surface roughness, the more deformation work is required to separate the surfaces in contact. Figure 4 indicates that greater tooling draft angles result in lower ejection forces in the SL moulding process.

Both sets of results also shows that for the all the experiments the application of release agent prior to moulding (applied prior to shots 1 and 11) does reduce the ejection force. A gradual increase in force is then noted in subsequent shots as the release agent is removed from the tool surface. 


\section{Conclusions}

\subsection{Surface Roughness}

The results from the measurement of the surface roughness of the layer thickness tools indicate that a larger layer thickness results in a rougher surface. The post-moulding tests for surface roughness show that there is no noticeable change in surface roughness after the cores had been used for injection moulding for either the layer thickness or draft angle tooling inserts. The fact that there appears to be no change in surface roughness after moulding seems a little surprising at first. However investigations into heat transfer in the core during moulding show that the heat from the polypropylene penetrates the SL core at a very slow rate (Hopkinson, 1999). By ejecting the part after a 40 second cooling period the surface of the core is above its $\mathrm{Tg}$ at the time of ejection and acts in a rubbery way. This means that the two materials will give way as the moulding is pushed across the core's surface and return to their natural positions after the moulding has been fully removed.

\subsection{Ejection Forces}

The lowering of ejection forces with the application of a silicone release agent is of very little suprise as this lowers the friction experienced between the mould and part surfaces. The results do show that this agent 
is not removed entirely by one shot and rather allowing a gradual increase in the ejection forces experienced over a number of shots as it is steadily removed.

The increase in ejection force with larger layers is consistent with the higher surface roughness measured in these tools. A larger layer thickness results in deeper surface peaks and troughs which results in a greater quantity of material needing to deform to facilitate ejection. This in turn leads to a higher ejection force.

The results show that the ejection forces are lower for greater draft angles. This is of no surprise as the use of draft is usually used to reduce the force required for removal of the part from the mould (Rees, 1995).

These experiments have shown that by comparison of the two sets of results the effect of build layer thickness is greater than the tooling draft angle on the part release forces in SL injection moulding. This difference is likely to be due to the effect of changing the respective variables on the surface roughness of the SL tool surface. This is demonstrated by comparison of Figures $5 \& 6$.

The research presented in this paper indicates that smaller layer thicknesses and greater draft angles result in lower ejection forces and may reduce the possibility of tool failure during part ejection. Unfortunately building parts with smaller layers involves extra time and cost while the use the use of a high draft angle places compromises on a parts intended geometrical design. 
However the results also show in both experimental cases (although much less so for the draft angle experiments) that a linear change of an experimental variable (the amount of draft angle or the build layer thickness) equates to a non-linear degree of change in the part ejection force. This may indicate optimum values for the experimental variables which would incur the lowest part ejection force whilst allowing a minimum disruption to a parts intended geometry (draft angle) and build time (layer thickness).

\subsection{Suggestions for further work.}

The surface roughness tests in this research showed results that did not indicate any wear incurred by the moulding process. However Polypropylene is a particularly non-aggressive moulding material and a more aggressive material (such as a glass filled polymer) would be more likely to cause wear to the low strength SL substrate.

Another polymer specific factor that would surely effect the ejection force experienced is the shrinkage. Although polypropylene is a crystalline polymer with a large percentage of volumetric shrinkage it is very slow to occur. A large majority of this may occur after the part has been ejected from the mould. The use of a polymer with higher or lower in-moulding shrinkage may also effect the ejection force. 


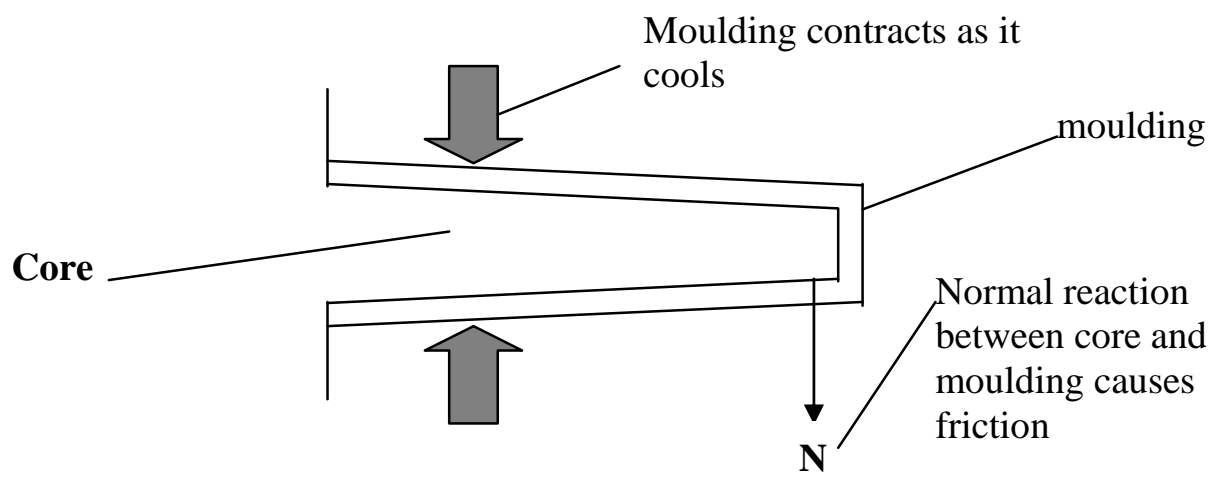

Figure 1: As the moulding cools it contracts onto the core

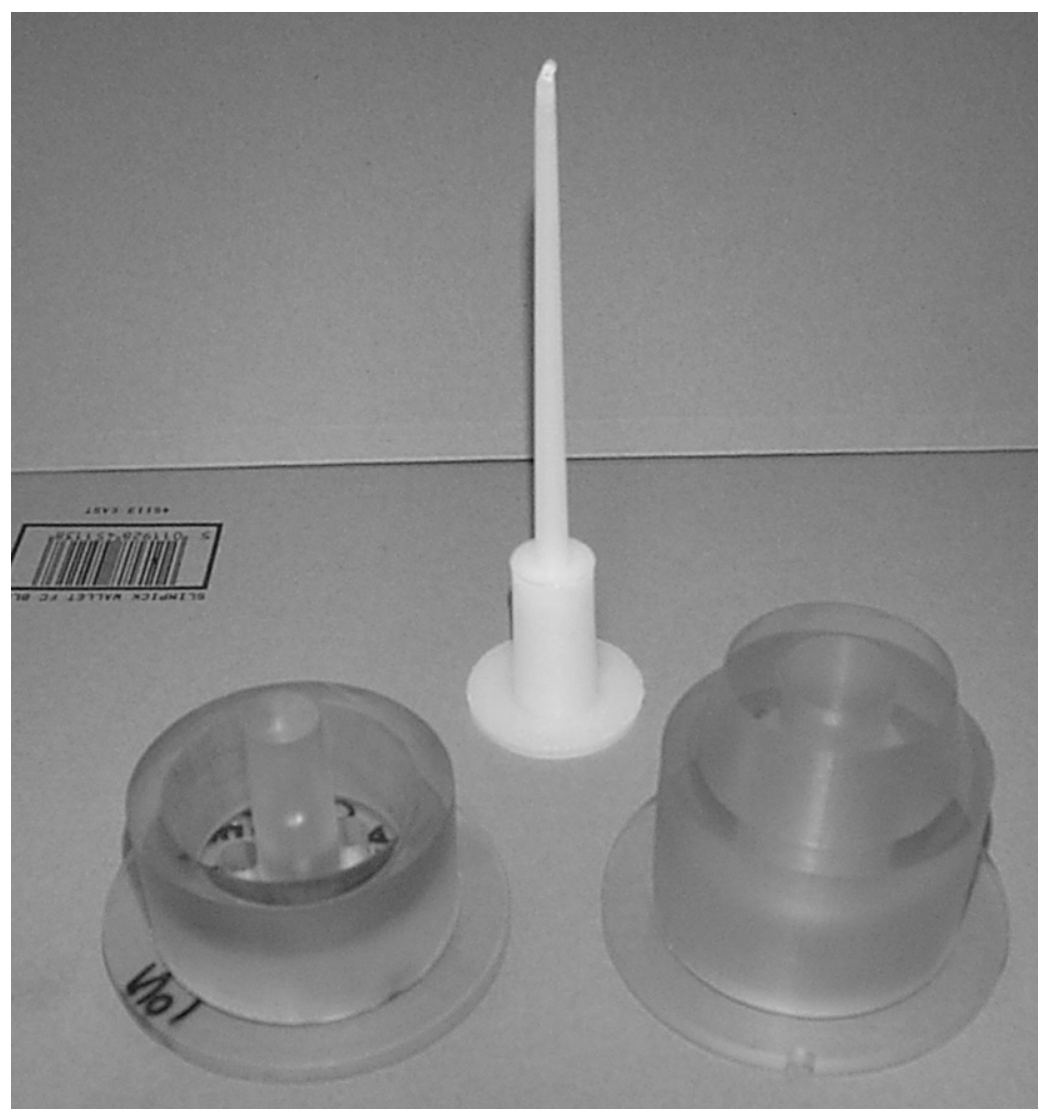

Figure 2. Core and cavity inserts along with moulding including sprue 
Ejection forces of SL moulds of differing layer thickness with PP

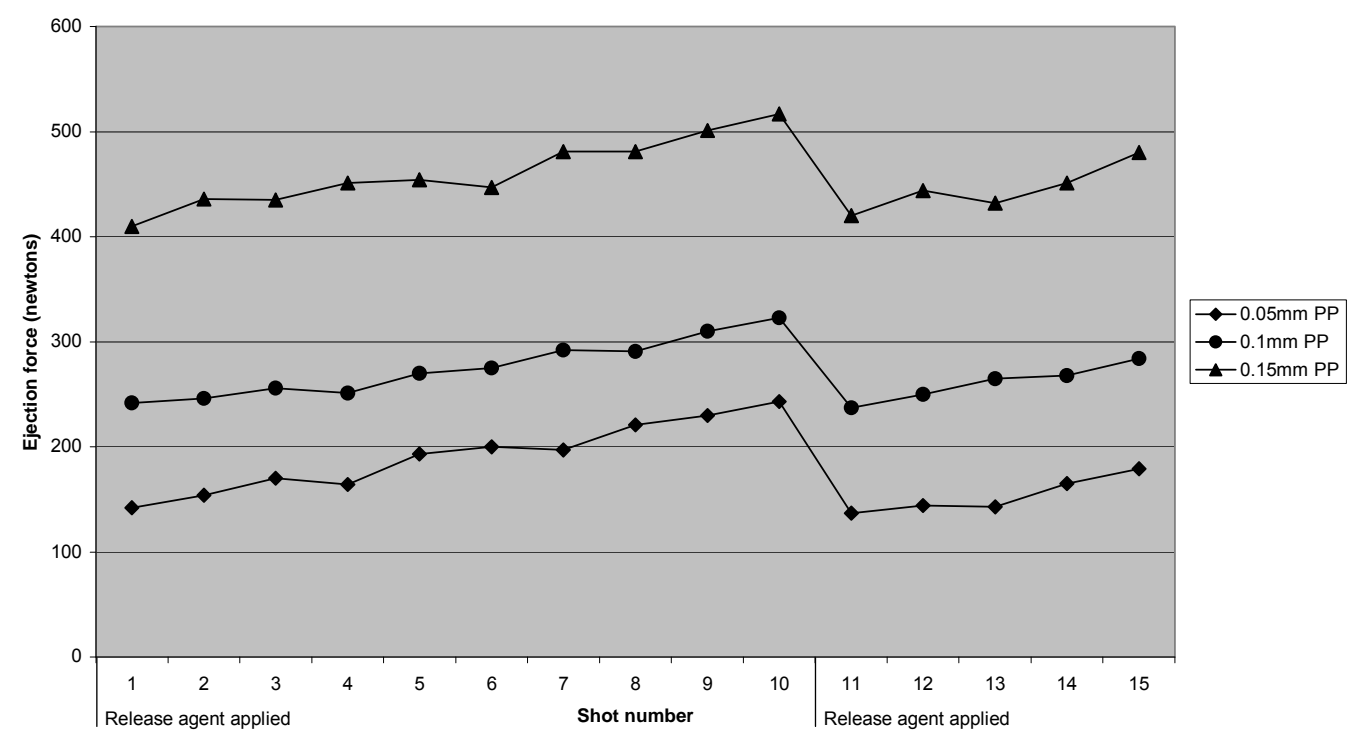

Figure 3. Graph showing ejection force against shot number for tools built with different layer thicknesses

Ejection forces of SL moulds of differing draft angle with PP

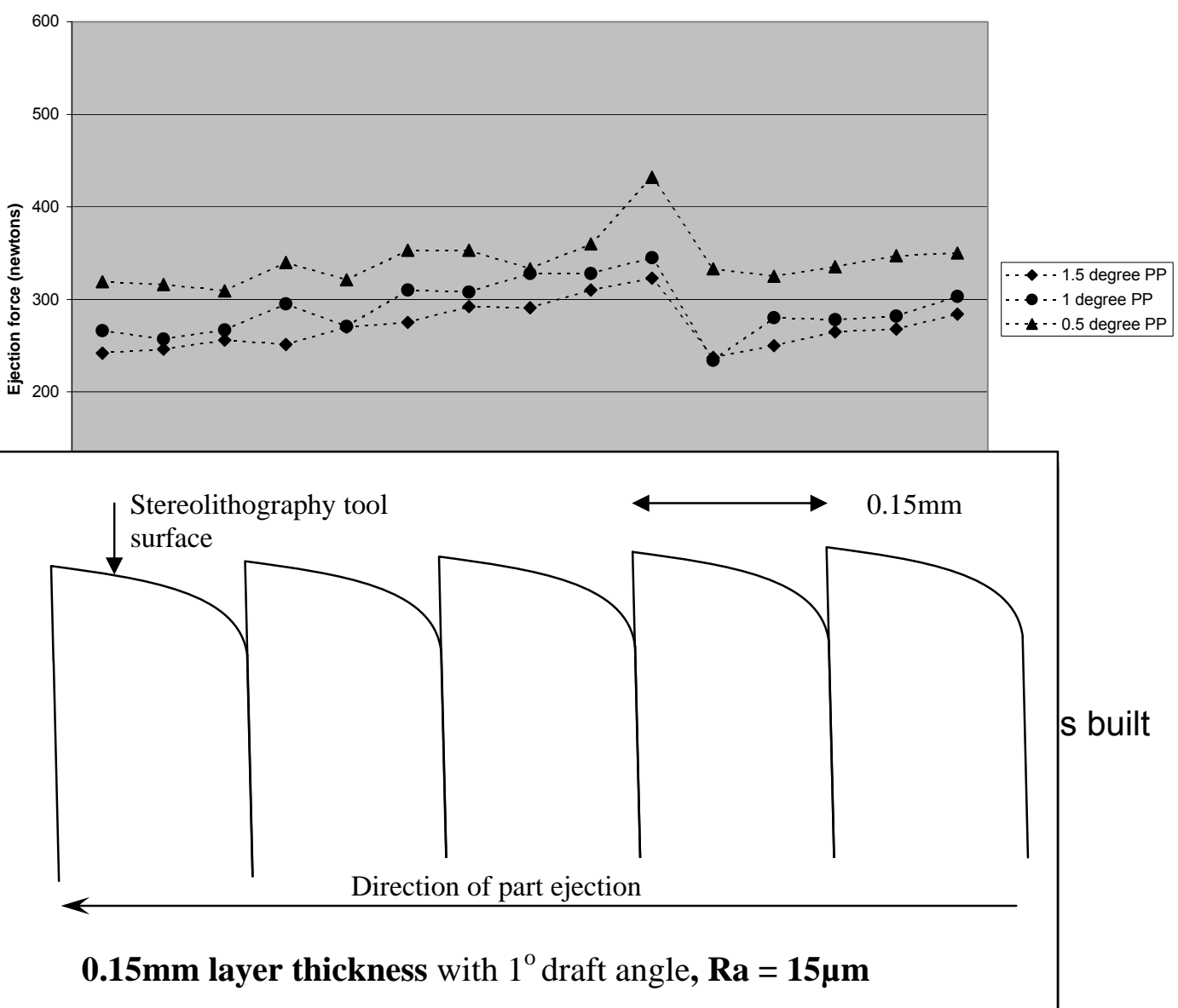



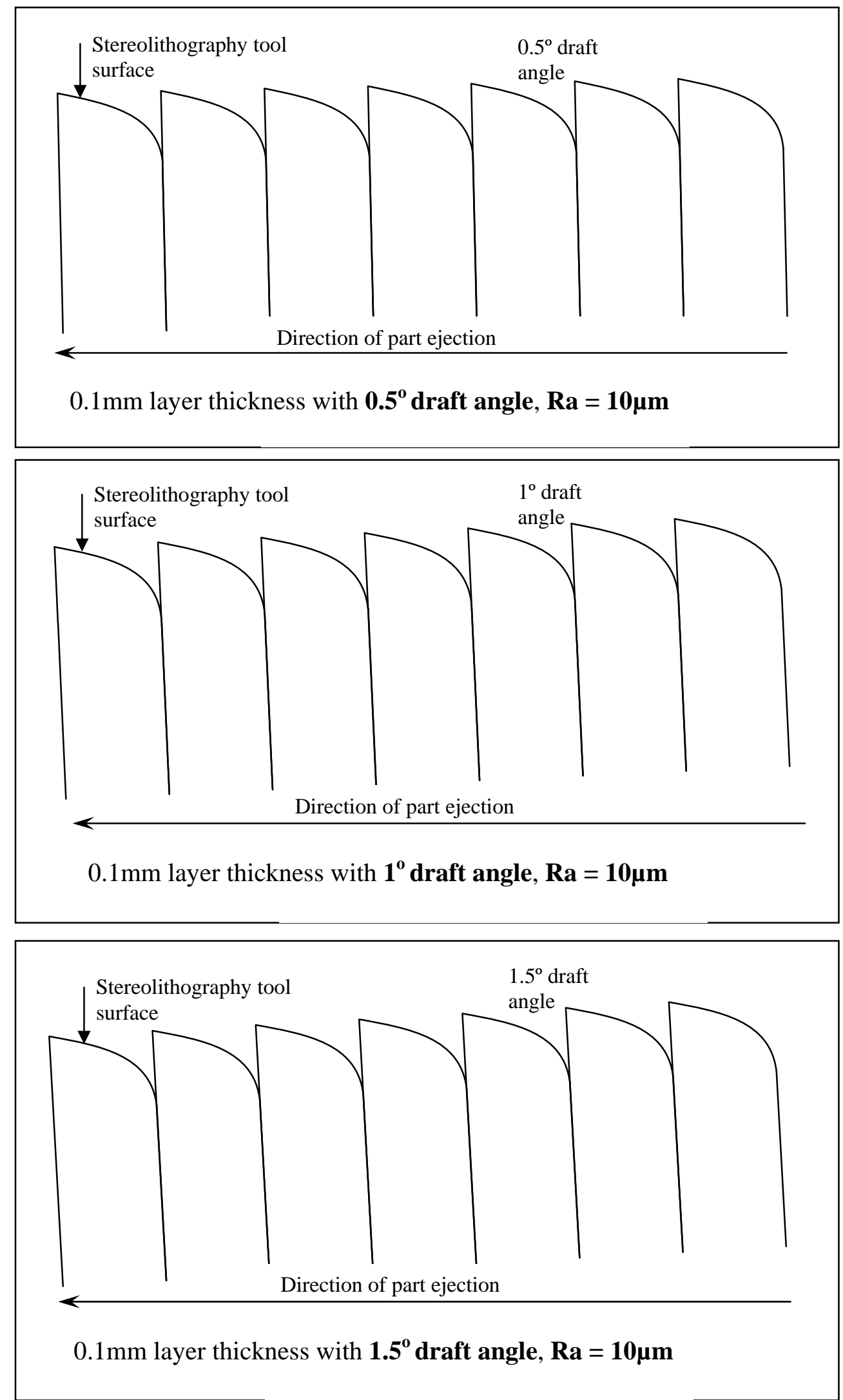

Figure 6. The effect of draft angle orientation on tool surface Ra. 


\section{References}

Decelles, P. and Barrit, M., 1996, Direct AIM ${ }^{\mathrm{TM}}$ Prototype Tooling

Procedural Guide. 3D Systems, Valencia, CA, USA.

Heath, J., 1996, Direct tooling for injection moulding. Proceedings of the SME RP\&M Conference Dearborn, Michigan, USA.

Hopkinson, N. and Dickens, P.M., 1998a, Study of Ejection Forces in the direct $\mathrm{AIM}^{\mathrm{TM}}$ Process. Proceedings of the $9^{\text {th }}$ Solid Freeform Fabrication Symposium, Austin, TX USA.

Hopkinson, N. and Dickens, P.M., 1998b, Research into Part Ejection in the $\mathrm{AIM}^{\mathrm{TM}}$ Process. Proceedings of the Time-Compression Technologies '98 Conference, Nottingham, UK.

Hopkinson, N. and Dickens, P.M., 1999, Injection Mould Tooling in Hours/Days Rather than Days/Weeks. Proceedings of the World Manufacturing Congress Conference, Newcastle-upon-Tyne, UK.

Jacobs,P., 1997, Recent advances in rapid tooling from stereolithography. $7^{\text {th }}$ International Conference on RP, San Francisco, California. USA. 
Jacobs, P.F., 1996, Recent Advances in Rapid Tooling from

Stereolithography. Proceeding of the 2nd National Conference on Rapid

Prototyping and Tooling Research, Buckinghamshire College, UK.

Jacobs, P., 1997, Recent advances in rapid tooling from stereolithography. $7^{\text {th }}$ International Conference on RP. San Francisco, California. USA.

Janyanthi, S., 1997, Stereolithography Injection Moulds for Direct Tooling. Proceedings of the 9th European Stereolithography Users Group Meeting

Luck, T., Baumann, F. and Baraldi, U., 1995, Comparison of downstream techniques for functional and technical prototypes- fast tooling with RP. Proceedings of $4^{\text {th }}$ European RP Conference. Belgriate, Italy.

Menges, G., Morhen, P., 1986, How to Make Injection Moulds.

(Hanser Publishers)

Rees, H., 1995, Mold Engineering. (Hanser Publishers)

Roberts, S.D. and Ilston, T.J., 1998, Direct rapid prototyping injection moulding tools. Proceedings. of $7^{\text {th }}$ European Conference on Rapid Prototyping \& Manufacturing, Aachen, Germany. 


\section{Acknowledgements}

This research work is produced in association the IMS Rapid Development Project. IMS-28450. 
Word Count: 2856 